\title{
Religious Wear (Uniforms) in Psychiatry
}

\author{
Helen Bright \\ Medico-Legal Work, Doctors4Justice, Ipswich, UK \\ Email: drhelenbright@gmail.com
}

Received 5 January 2014; revised 1 February 2014; accepted 9 February 2014

Copyright (C) 2014 by author and Scientific Research Publishing Inc.

This work is licensed under the Creative Commons Attribution International License (CC BY).

http://creativecommons.org/licenses/by/4.0/

\section{(c) (i) Open Access}

\begin{abstract}
Uniforms represent more than just a body cover. There could be symbols of status, power, authority, values, beliefs, identity, wealth representation, self-protection, health and safety, suppression of individuality and identification on one hand by the wearer. The observers may perceive uniforms differently based on their experiences, expectations, education, perceptual ability, conformity, status, power, self-confidence, and need for trust and communication without barrier or judgment. Forty five adult mentally ill patients ( 21 female and 24 male) were administered questionnaires with Linkert Scale regarding how approachable or off-putting they find casual and religious wear in social worker. Significantly more patients preferred casual wear to religious. Chi squared test equals 28.689 with p value of less than $\mathbf{0 . 0 0 0 1}$ for four degrees of freedom.
\end{abstract}

\section{Keywords}

Religious, Uniform, Wear, Workwear, Clothes, Psychiatry, Mental Health, Judiciary; Military, Police, Clergy, Nuns, Politicians

\section{Introduction}

There are hundreds of published papers on the wearing of nursing and medical uniforms in mental health setting. With social changes in the 1960s and 1970s in United Kingdom mental health practice was changed from wearing of uniforms to casual smart wear for mental health workers [1] [2]. This is the first paper to the best of my knowledge on the wearing of the religious uniforms in mental health setting.

There are perceptions of uniforms by the observers based on their experiences [4], conditioning, expectations and reservations as well as mental state as in illness. Lavender [3] found that the change in dress for nurses led to a decrease in deviant behaviour (particularly violent incidents) and patient estrangement and an increase in the number of nurses in whom patients could confide. Researchers such as Rinn [5] showed that the greatest rates of maladaptive behaviours occurred during the white uniforms condition followed by the optional and street clothes conditions, respectively. Marcuse [6] described how following the abandoning of uniforms there 
was a dramatic upset where the children on a small unit made up uniforms, marched around the ward and adopted army-style procedures (e.g. kangaroo courts). His explanation was that disruption of authority led to aggression towards other children. However, it does not exclude other explanations such as relief of tension. Leff et al. [7] reported that patients very dependent on stereotypic information behaved less adaptively in the experimental social interaction with a nurse in street clothes due to their tendency to withdraw from the interaction.

In UK psychiatrists, mental health nurses, social workers and administrators do not wear uniforms because these are considered to be a barrier to trust and communication [8] [9]. In addition, General Practitioners, paediatricians and many medical consultants do not wear white coats. UK is not a secular state although the majority of people have secular views. Considering the controversy in findings, different settings and methodology as well as lack of any study regarding religious wear a study was conducted to find how approachable do patients find actor wearing casual wear or religious.

\section{Method}

\subsection{Questionnaires}

Ethics committee member, psychiatrist gave the go ahead for the study using two questionnaires. Linkert scale response was required to a short questionnaire with photographs of actors dressed in casual or religious wear. To control for sex of social worker one questionnaire had female actor dressed in casual wear and male actor in religious dress (Christian priest). Another questionnaire had the same male actor dressed in casual dress and the same female actor this time dressed as a nun (Christian). Forty five patients participated and two declined on account of not feeling that well on the day. All attended community mental health outpatients in England, United Kingdom. At one end of the Linkert scale was term "Most approachable" and on the other end "Most Off-putting”. Patients had to put a line across it to indicate their preferences.

\subsection{Results}

Twenty four male and twenty one female patients participated.

The age groups were:

16 - 25 years old seven patients

26 - 35 years old six patients

36 - 45 years old thirteen patients

46 - 55 years old fourteen patients

56 - 65 years old five patients

Patients were not selected by the study but the age distribution reflects that the outpatients service is provided for 16 - 65 years old patients living in the community.

Thirty two patients completed questionnaire A (female in casual dress, male as a priest) and thirteen questionnaire B (female actor dressed as a nun and male actor in casual clothes).

Twenty six patients found religious wear made the social worker (actor) less approachable, and ten patients preferred religious wear to casual wear. In two cases both casually dressed and religious dress were found to be equally off-putting. Seven patients found social worker dressed in casual or religious dress equally approachable. Not a single patient was neutral regarding both casual and religious dress. Chi squared test for all five possible answers with four degrees of freedom was 47.11 and $p$ value less than 0.0001 based on the assumption that there were no differences in the numbers in either of the five categories. If hypothetical neutral position is excluded Chi squared for three degrees of freedom is 28.689 and p less than 0.0001 .

Comparing those 26 with preference for casual dress with those who prefer clergy and the third group where both religious and casual wear is found equally off-putting or approachable Chi squared value is 12.133 for two degrees of freedom and p equal to 0.0023 .

\section{Discussion}

This is not just a small study but in a changing world. Secular views may be on the increase in some parts of the world but what about the significance of religious uniforms and to whom does it matter and how? Discussion below is an attempt to describe some of the significance as it appears to the writer. It is not complete as other mental 
health professionals would have their own insights, as would others.

\subsection{Mentally Ill Person}

\subsubsection{Barrier to Communication}

It has already been established by most scientific research that no uniforms should be worn in mental health setting. Thus one finds that doctors, nurses, social workers and administrators in England have not worn any uniforms for at least thirty years. Uniforms are a barrier to communications as in "us and them". With impaired communication there is a much decreased chance of effective diagnosis and treatment. The consequences of wearing uniform defeat the purpose of employment.

Reminder of trauma Men raped by clergy as children may experience flashbacks, panic attacks when reminders of trauma are presented to them.

Diagnostic and Statistical Manual of Mental Disorders TR IV lists diagnostic criteria for mental illnesses. Under Post-traumatic stress disorder one is able to find that avoidance is one of the groups of symptoms. Avoidance means avoiding situations and people that act as reminders of the trauma. Talking about trauma is also a reminder. Even thinking about appointments with professionals when such traumatic events may be discussed can lead to anticipatory anxiety in patients with Post-traumatic Stress Disorder. Some patients have sleepless night(s) and even start vomiting when so anxious.

There is no point in multiplying the barriers to communications with mentally ill people and wearing of religious uniforms does just that for many.

Reminders of abuse by clergy include religious uniforms. The result can be severe panic attacks experienced by patients. Panic attacks are associated with higher mortality from myocardial infarction too. Therefore, religious uniforms represent health and safety risk in mental health setting that is preventable.

\subsubsection{Uniform Symbolic of Uniformity of Values for the Group Wearing the Same Uniform}

It is would be recognized by most mentally ill people that uniform poses obligations on the wearer of uniform to conduct themselves consistent with the values of the institution it represents. This involves the sacrifice of individuality of the wearer.

The issues of trust arise out of this situation. Person, who has given up their individuality and made considerable efforts at it, is unlikely to uphold another person's right to his/her deviancy from norm (as in mental health issues) and especially so where the degree of deviance from the norm can be considerable (healthy or unhealthy).

\subsubsection{Health Issues and Stereotyping}

There may be health issues that patients would not disclose because of the fears of what religious person may think about them, for example, sexual issues, family planning, abortions, blood transfusions, epilepsy, mental illness causing behavioural transgressions, hearing voices, feeling controlled by outside forces (as in some cases of schizophrenia) and so on.

\subsection{Reprisals}

Disclosing history of abuse by clergy to members of clergy has been very risky for victims. Now it is known that canon law requirement has been to keep the history of abuse secret from other people (including police) or risk excommunication.

In communities where clergy have influenced even access to jobs fear of reprisals has been very real and not evidence of paranoia. Unemployment creates depression, and exacerbates mental illness. It can also lead to increased suicide risk.

Threats of reprisals against the victims of abuse by clergy are some of the factors that prevented access to state justice system. Mental health is damaged by chronic injustice and this applies to victims, their families, and friends.

It has been argued by some lawyers that aiding and abetting the crimes of child abuse happened at the top of religious hierarchy through the canon law defects as well as the lack of effective child protection measures following the disclosures of abuse. The offenders were allowed to work not just within the same religious organization but with children too while the risk of reoffending remained the same. As crimes were not reported to police there would be no Criminal Records Bureau check that would reveal anything. 


\subsubsection{Authority and Power v Right to Individuality}

Healthy attitude is to accept that each person is an individual. Religious uniforms represent authority and power in mental health setting as determined by state that permits it. Religious uniforms are misplaced in mental health setting as it actually ignores patient's need to be considered as an individual who may actually hold very different beliefs and whose need at the time is his own health foremost and not to be preoccupied with what the needs of the religious person wearing religious uniform are. It is impossible to be faced with a person wearing religious uniforms and not notice it unless one is blind or has other rare perceptual disorders. This means that mentally ill person is expected to adjust themselves to the expectations of the religious mental health worker wearing the uniform irrespective of their desire, need or ability to do so.

\subsubsection{Equality Issues through Role Modelling}

Mental health workers are like teachers in that they represent role models. It is unhealthy to act as a role model for values that are against equality for women, those of different ethnic groups, sexual orientation, different beliefs and so on. Religious uniforms stand for patriarchal values and outdated values which are not in keeping with the laws on equality.

\subsection{Anxiety}

Anxiety is common in many mentally ill people and introducing more anxiety by wearing of religious uniforms causes worry to patients and needless suffering which could be prevented.

Putting patient in a situation where he/she has to deal with making of formal objections to wearing of religious uniforms also presents the task for mentally ill that they may not be able to do. It is unreasonable to expect mentally ill, vulnerable people to assert their rights and fight the system when even healthy professionals are scapegoated and destroyed when they attempt to do it.

\subsubsection{Provocation and Violence}

It can be said that religious uniforms can represent provocation to some patients who already may have problems with impulse control for various reasons such as high stress levels. Some patients can be paranoid and grandiose too which in itself can lead to poor impulse control and aggression towards those who are considered irritants (like those wearing uniforms).

There are various cases reported of murders of nuns and priests by mentally ill who had a mixture of paranoid and religious delusions. The case of Mark Bechard is a well-known case and there are many others. He killed at least two nuns in the same day and wounded seriously more. Not all cases of attacks by mentally ill on clergy are reported in literature but may be reported to police.

\subsubsection{Mental Handicap/Learning Disability}

It is recognized that there are people who have severe cognitive handicaps, are very vulnerable and it can be accepted that they may be totally unable to object themselves to the wearing of religious uniforms or to even instruct anyone else to object on their behalf to the wearing of religious uniforms by mental health workers. There are sometimes large numbers of children with learning disabilities who suffered abuse in some religious institutions. Reminders of trauma may not be verbalized but manifest themselves in behavioural deterioration which would be difficult for professionals to manage or even understand in patients with communications problems.

\subsection{Suicides}

1) Suicides can result from untreated mental illness. When barriers to communications exist as they do in human society and medical institutions for various reasons one finds increased suicide rates. Men have higher suicide rates in UK and there is social expectation that men cannot be emotional, or sad. Gender inequality is reinforced by most major religions and for both sexes in a different manner. Sense of hopelessness may arise in patients when they see that mental health institution they want and need to trust upholds values detrimental to their health. Some religious people do not recognize manifestations of mental illness but see it as possession by evil spirits which is offensive in itself to mentally ill.

2) There appeared to be an increase in suicides following appointment of a nun wearing religious uniform over period of four years in one local authority in London. The average suicides went up from 15.2 to 17.5 per year 
according to figures obtained from the Office of National Statistics.

\section{Inefficient Use of Taxes}

It is now known that even as much as $50 \%$ of UK population would at some point in their life experience mental distress. Most cases of mental distress would not come to psychiatrists but would be dealt with by GPs or by people themselves. The majority of those people would be working most of their lives and paying taxes with which they would support the system that is not supporting them at all times. When wearing of religious uniforms in mental health is detrimental to patients it follows that using tax payers' money for salaries of people wearing them is inappropriate and against the interest of the tax-payer too.

\subsection{Doctors}

\section{Diagnosis and Treatment}

1) When there is no communication or decreased or impaired communication between patient and doctor wrong diagnosis and wrong treatment may result. Wearing of religious uniforms impairs patients' communications with professional wearing it, and even with those not wearing the religious uniform that become associated with it in their minds. "They are all the same" is what some say referring to all the staff after a disappointment. This occurs in depressed patients and is known as catastrophizing. The point here is that implications of wearing uniforms in mental health are wider than one might think at first.

2) It is already established that not wearing uniforms is associated with better compliance with treatment, less absconding from wards, less self-harm, less violence from patients. See paper by Roger C. Rinn [5].

\subsection{Power}

1) Some doctors can be unfair and stigmatize mentally ill patients. This means that government policy of leaving mentally ill at the mercy of local National Health Service Trust policy making is misconceived when it comes to the wearing of religious uniforms by mental health professionals. There is already discrimination against mentally ill people and it is unlikely that all NHS Trust administrators would care about mentally ill to the same extent, or that the majority of doctors would care about mentally ill as much as about other patients assumed to be sane.

2) Medical profession is self-regulated profession (medical regulator is accountable to Parliament) which means that it is possible to get rid of dissident voices amongst doctors over a period of time through the sham peer review process using medical regulator, the General Medical Council. GMC is religiously biased. Medical profession was at one point in history exclusively regulated by clergy. Now clergy can and do work at medical regulator. While some members of clergy do declare their interests others do not. The examples of those who did not declare their interests was a Scientologist (not a medical doctor), and a preacher (a medical doctor) (who also joined GMC Fitness to Practise Panel while being investigated by them).

Raising the issue of religious uniforms has been a dissident voice which puts patients first and not doctors or other mental health professionals wearing religious uniforms.

British Medical Association is conformist and it would support strike for doctors' pensions for their members but unlikely to take actions on human rights for patients and especially not mentally ill or to defend doctors who are human rights defenders for their patients.

Medical ethics is that patients come first, but it does not happen in reality when religious uniforms are worn by mental healthcare workers. However, it looks very nice in print that patients come first.

\section{Values and Beliefs}

Religious uniform may represent the values that mental health professional holds important and prefer to hold in isolation from other thoughts giving rise to cognitive dissonance such as thoughts how bad it is for the patients and staff as well as the community (public interest). Cognitive dissonance plays a role in many value judgments, decisions and evaluations. Becoming aware of how conflicting beliefs impact the decision-making process is a great way to improve ability to make faster and more accurate choices. This ideal awareness is not something that is likely to happen in medical institutions dominated by men (General Medical Council in over 150 years never had a woman President or Chief Executive) or where women are chosen for their adherence to the same values and biases as men already there have. All major religions are patriarchal and dear to some medical men for that very reason. But not all medical men are the same. 


\subsection{Politicians}

\subsubsection{Votes}

If it is accepted that religious people vote and that getting those votes could make one believe that by having religious bias at the expense of the mentally ill would lead one to have more power if elected. The assumption here is that religious people would prefer the rights of religious uniform to that of mentally ill persons. There is no evidence that in the setting of having the knowledge that uniforms (religious and non-religious) are harmful in mental health setting it would result in the majority of religious people being unreasonable and demanding special privileges to be given to those who wish to wear religious dress. In fact, the latest statistics show that the majority of UK citizens have secular views. In addition Catholic church has stated that it is not necessary to wear religious clothes when working in the community. Over the last 40 years there have been attempts within the Church of England to do away with archaic wear in usual activities performed by clergy (outside mental health setting).

A small petition was signed by members of different religions asking for religious dress not to be worn when working with mentally ill. General Medical Council's (GMC) response despite their obligations under Medical Act 1983, section 1 to act in public interest was that they do not tell doctors what to wear. This is not quite true. They did have in their guidance Good Medical Practice issued to doctors that religious dress should not be worn if it impairs communications and referred to Muslim full body and face cover up. When faced with demand for equal treatment of all religious dress they did sham consultation and omitted responses from organization such as National Secular Society which represents thousands of people in their membership but millions in the country who hold the same values of patients coming first. GMC decided to ignore them completely.

\subsubsection{Power}

Most religions are patriarchal and that appeals to some politicians who may identify with such values. But many would not if representative of the population and if asked and informed properly.

\subsubsection{Wilful Blindness}

Some politicians may have been well informed and knew that religious uniforms were, really, not such a good idea in mental health setting but avoided dealing with the issues by creating a good work wear policy (as they did for general medical and surgical wards in the interest of hygiene) because of cognitive dissonance and desire to eliminate it by extolling the virtues of religion because of all the previous personal investments made in religion. Despite the repeated requests for policy to be reconsidered they refused during Labour government. When Labour was voted out of the office they realized some of the reasons why and got themselves a leader who is not religious.

\subsection{Religious Institutions}

\subsubsection{Free Marketing}

When religious uniforms are seen in the setting where some good is done (health and social care) religious institutions get free marketing because religious uniforms are symbolic of religious institutions and their values. Doing the job of mental health professional while wearing the religious uniform could be perceived by observer as the work of religious institution.

\subsubsection{Power}

Having the "right" to wear religious uniforms when other mental health professionals are not allowed to do so places religious institutions in the positions of power and special privilege. In fact, there is no such right in law. Article 9 of European Convention on Human Rights is not an absolute right but a qualified right.

It becomes impossible not to consider the needs of the religious person in all interactions between professionals and patients when religious uniforms are worn. Both professionals and patients have at all time to consider what to say and what not to say in fear of offending the religious and the institutions behind them. Like in dysfunctional families one is walking on egg shells.

It is so very easy to offend the religious.

\subsubsection{Financial Benefit}

Religious uniforms are also provocative and divisive. 
Firstly, scientifically minded professional is provoked to react to it. Similarly, person with sense of justice could do the same.

Secondly, it is possible to eliminate competition from scientifically orientated professionals by claiming religious rights, establishing those rights as dominant rights and thereafter benefiting financially when scientific competition is firstly discredited and subsequently destroyed and eliminated from the workforce.

\subsubsection{Right to Expression of Religious Belief}

While public recognize the right to religious beliefs public expects politicians to put their health first without excluding the health of mentally ill people. This would be in keeping with European Convention on Human Rights Article 9, having the proper balance of different rights along with the current government policy of compassion and the policy to reduce suicides.

\subsubsection{Image and Values}

In UK so far, the social and cultural background of institutional administrators determined preference for the religious uniforms while disregarding the needs of the mentally ill. No policies were created that eliminated the wearing of religious uniforms anywhere in UK while it has been acknowledged that no uniforms are worn in mental health setting normally.

\subsubsection{Power}

Where there is power there is potential for abuse of that power. Low social status of mentally ill people and low power of mentally ill enabled religious bias to dominate sometimes with fatal consequences. Religious uniforms may be symbolic of values to which some administrators aspire.

\subsection{Justice System}

\subsubsection{High Prevalence of Abused Males}

In a number of studies in penal settings in Europe and elsewhere it has been established that there is a high prevalence of men who have suffered abuse (emotional, physical and/or sexual) as children. The incidence is as high as $70 \%$ in some studies.

Considering the link of traumatic experiences to that of offending one would have to consider the impact of religious uniforms when visiting prisoners some of whom may have suffered abuse by clergy.

There are men in UK prisons who have killed clergy members following experiences of abuse by them.

\subsection{Military}

Murders by religious psychiatrist wearing religious clothes

2009 USA Army base incident (Fort Hood mass shooting by Dr Nidal Malik Hassan, psychiatrist who killed 13 people and wounded 29) is a good example of failures to assess the risk to army personnel.

Here psychiatrist was seeing army personnel some of whom would have Post-traumatic stress disorder as the result of the war in the country where predominant religion was Islam, the same as that of the psychiatrist who dressed in ethnic clothes identifying him as a Muslim. Patients with Post-traumatic stress disorder can be very irritable and provocative and religious uniform is provocative itself. The combination was fatal for many.

\subsection{Police}

\section{Uniforms deviation}

Police have standard uniform but deviations occur with religious police officers who have been allowed by UK courts, for example to wear Sikh turban.

\subsection{Security}

\subsubsection{Identity}

It may be impossible to identify person who is completely covered up including their face in religious/ethnic dress. 


\subsubsection{Prevention of Violence}

It is known that clergy members are at risk of violence more than any profession including police in UK. Economic and Social Research Council funded research found so [10], published their findings and newspapers publicized it as well, but politicians did not change the policy of religious privileges. Clergy are less at risk within the walls of the religious institutions than outside the buildings, perhaps, indicating that boundaries are helpful in reducing violence against the clergy.

\section{Self-Criticism}

This is the first study of its kind as far as the author is aware and now, one has the benefit of some of the comments written by patients on questionnaires, without being asked to do it, about actors:

"looks a bit stuck up and sad"- -this is about a female actor in casual smart dress

"he is from the night off the living dead he is too pale as well"- this comment is about actor dressed as a priest.

And from another patient opinion on approachability of these two actors: "Very good, all very pleasant".

A mystery comment: "YS09815"

And one easy to understand:

"Comment

I feel I would hopefully be open to individual's differences \& attempt to be respectful to this. However given the above religious links \& I'm not sure how easy I would find it to share deeply private things which from religious perspective may offend or seem wrong”.

Maybe, one should have just one photograph of a smiling person, with ruddy cheeks and edit it digitally for dress changes only.

A study with a larger number of patients may give more scope for statistical analysis and attempts to correlate preferences with factors such as age group of patient (This data was collected but not analyzed because of the small numbers). Patient selection (for example, sexual dysfunction clinic), if that is of interest, may produce different results.

\section{Acknowledgements}

Dr Tim Hull, Consultant Psychologist made useful suggestions and criticisms regarding the design of the study. I am grateful to all the participants in this study who took time to give their opinions freely and frankly. Survivors Network of those Abused by Priests in USA provided support for the findings.

I am also especially grateful Mr and Mrs D. Jevtic, Ms Sue Hope-Boreland, Ms Jade Munslow and Dr Adrian Garfoot, all for their different and valuable contributions.

\section{References}

[1] Allan, C., Heffernan, C., Pallent, S. and Weaver, L. (1992) Uniforms: A Strange Custom? Nursing Times, 88, 51.

[2] Smith, D. (1990) Uniforms: Worn Out. Nursing Times, 86, 32-35.

[3] Lavender, A. (1987) The Effects of Nurses Changing from Uniforms to Everyday Clothes on a Psychiatric Rehabilitation Ward. British Journal of Medical Psychology, 60, 189-199. http://dx.doi.org/10.1111/j.2044-8341.1987.tb02730.x

[4] Trauer, T. and Moss, A.V. (1980) Psychiatric Patients' Opinions of Nurses Ceasing to Wear Uniform. Journal of Advanced Nursing, 5, 47-53. http://dx.doi.org/10.1111/j.1365-2648.1980.tb00209.x

[5] Rinn, R.C. (1976) Effects of Nursing Apparel upon Psychiatric Inpatients’ Behaviour. Perceptual \& Motor Skills, 43, 939- 945. http://dx.doi.org/10.2466/pms.1976.43.3.939

[6] Marcuse, D.J. (1967) The “Army” Incident: The Psychology of Uniforms and Their Abolition on Our Adolescent Ward. Psychiatry, 30, 350-375.

[7] Leff, H.S., Nydegger, R.V. and Buck, M. (1970) Effect of Nurses’ Mode of Dress on Behaviour of Psychiatric Patients Differing in Information-Processing Complexity. Journal of Consulting and Clinical Psychology, 34, 72-79. http://dx.doi.org/10.1037/h0028788

[8] Klein, R.H., Pillsbury, J., Bushey, M. and Snell, S. (1972) Psychiatric Staff: Uniforms or Street Clothes? Archives of General Psychiatry, 26, 19-22. http://dx.doi.org/10.1001/archpsyc.1972.01750190021005 
[9] Brown, J.S. and Goldstein, L.S. (1967) Nurse-Patient Interaction before and after the Substitution of Street Clothes for Uniforms. International Journal of Social Psychiatry, 14, 32-43. http://dx.doi.org/10.1177/002076406801400104

[10] Stanko, E.A. (1998) Taking Stock What Do We Know about Violence? ESRC Violence Research Programme, Brunel University, Uxbridge. 